\title{
Gender Gap in Integrated Watershed Management Project
}

\author{
Shikha Singh* and Neelam Bhardwaj \\ Department of Agricultural Communication, G.B. Pant University of Agriculture and \\ Technology, Pantnagar, Uttarakhand (263145), India \\ *Corresponding author
}

\begin{tabular}{|l|}
\hline Ke y w o r d s \\
$\begin{array}{l}\text { Watershed, Gender } \\
\text { gap, Gender } \\
\text { equality, Decision } \\
\text { making }\end{array}$ \\
\hline Article Info \\
\hline $\begin{array}{l}\text { Accepted: } \\
\text { 04 August } 2018 \\
\text { Available Online: } \\
\text { 10 September } 2018\end{array}$ \\
\hline
\end{tabular}

A B S T R A C T

In the recent decades, as a consequence of environment degradation and resource depletion in the hill areas due to soil erosion and denudation of hill is resulting in increased struggle to produce good amount of food grain. The migration of male member of the family for better livelihood options underlies the dependence of rural economy on women's shoulders. Deforestation and low water availability adds to their problems by spending more time in collection of fuel, fodder and fetching water. Women participated to a considerable extent in watershed activities, yet their participation in decision making was not up to the mark. The study was conducted on Uttarkashi and Bageshwar district of Uttarakhand. Six villages were selected using simple random sampling. Primary data had been collected by conducting interviews with 150 women and 150 men in selected villages located within the watershed. It was revealed from the study that management practices mostly done by women in the study area but its ownership and control were in men's hand. Men had a greater access and control over resources as compared to women. This might be due to deeply rooted inequalities in socio-political participation of women, male dominancy, social stigma; stereotype mindset because of this, the status of women was very poor in decision making. Considering this situation, the researcher felt the need to explore the gender differences in rural areas, particularly in hill areas of Uttarakhand. Therefore, the key objective of the study is assess the gender gaps in the implementation of different activities of IWMP

\section{Introduction}

According to "Draft National Policy for Women in Agriculture (2008)", women constitute 40 per cent of the agricultural workforce and this percentage is rising, currently 53 per cent of all male workers but 75 per cent of all female workers and 85 per cent of all rural female workers are in agriculture. Women as economic providers, caregivers and household managers, are responsible for ensuring that their families must have basic resources for their daily lives. They are often the managers of community natural resources, and have learned to protect these resources in order to preserve them for future generations (managers of sustainability).

Although, women play a vital role in conservation of natural resources due to their larger dependency on them. 
Due to their distinctive engagements with the natural environment, women's experience and knowledge are critical for environment management (UNEP, 2004). Using gender perspective and enabling the integration of women's knowledge related to environment will increase the chances of environmental sustainability. It is essential for natural resource management projects such as Integrated Watershed Management and Joint Forest Management projects need to integrate gender perspective at the institutional as well as field level. Since gender concerns are often the result of a male biased society, culture and traditions.

Women are important stakeholders in watershed management. However quantifying the role of women and their participation in integrated watershed management remains a challenge at all levels of planning, management and utilization of watershed resources (Critchley, 1991; WEDO, 2003). Although Integrated Watershed Management (IWM) is an approach that promotes the coordinated development and management of water, land and related resources in ways that are efficient, equitable and environmentally sound, quantifying the role of women and their participation in IWM planning has remained elusive over the years (CAF, 2010).

Many government organizations, nongovernment organizations (NGOs) and development agencies have made an efforts to do this, but have had limited success due to lack of appreciation of the remarkable environmental management skills of women in Uttarakhand. Taking into account the different roles and responsibilities of men and women is critical to the sustainable management of natural resources as well as the success of NRM projects and prorgrammes. There is needed to be aware about NRM projects which may affect women and men differently due to their rights, roles and responsibilities. Women have a unique understanding of natural resources but not specifically included into the design of policies and programmes. When planners and projects staff recognize this and integrate women's concerns at all stages, it will lead to greater success of project.

Therefore, it is worthwhile to understand how important it is to consider gender perspective in projects that focus on management of natural resources such as integrated watershed management programme. The paper brings special attention to gender gap in integrated watershed management project.

\section{Materials and Methods}

The present paper has been based on primary data. Uttarakhand has been selected as the universe of the study. There are 13 districts in Uttarakhand which are grouped into two divisions: Kumaon and Garhwal. Out of 13 districts two districts namely Uttarkashi and Bageshwar were selected purposively as the locale for the proposed study. There are Krishna; Muradi and Bhatiya villages from Uttarkashi district and Tallihat, Matena and Kausani from Bageshwar district were selected using simple random sampling. A detailed primary survey of the study area had been conducted and from these six villages 300 respondents were selected by using PPS (Probability Proportionate to Size) method. For the collection of data, a structure schedule was developed for the respondents. Primary data had been collected by conducting interviews with 150 women and 150 men in six selected villages located within the watershed.

\section{Result and Discussion}

The results in Table 1 indicated that as far as watershed management activities are concerned labour work was performed by both 
men and women jointly. With the inception of IWMP project in the study area various watershed management activities have been carried out there. The eight activities namely, terracing, counter bund, broad beds, slopping lands, stone barrier, nursery, organic manure application and mulching and tree planting were selected to know the responses of men and women. According to pooled data of both men and women responses, it was found that most of the watershed activities were carried out by women.

The data elucidate that in the activity terracing the participation of women was 41.67 per cent and 40.33 per cent by both men and women. The participation of men was only eighteen per cent. According to pooled data, it was found that the participation of both men and women in the activity counter bund was 52.67 per cent followed by women (37.33 per cent) and by men (10 per cent).

The participation of both men and women in the activity of broad bunds was 50.67 per cent and 39 per cent activities were performed by women. Only 10.33 per cent of the activities related to broad bunds were performed by men alone. The activity developing slopping land was performed by both men and women (43 per cent) followed by women only 37.67 per cent and 19.33 per cent by men. The activity construction of stone barrier was mostly performed by women (38.33 per cent).

The participation of men in the construction of stone barrier was 36.33 per cent and by both men and women was 25.33 per cent. Participation in nursery raising by both men and women was 48.33 per cent followed by women (42 per cent) and men (9.67 per cent) respectively.

The participation of women in the activity application of organic manure was 41.33 per cent and 31 per cent performed by both men and women. The participation of men in the application of organic manure was 27.67 per cent only. It was further revealed from the data that participation of women in mulching and tree planting activity was 39.67 per cent followed by 34.33 per cent by men whereas 26 per cent of men and women participated jointly in tree planting and mulching.

Table.1 Distribution of respondents according to participation in Integrated Watershed Management Project activities $(n=300)$

\begin{tabular}{|l|l|l|l|l|}
\hline S. No & Activities & $\begin{array}{l}\text { Overall }(\mathbf{n = 3 0 0}) \\
\text { Women } \\
\mathbf{f ( \% )}\end{array}$ & $\begin{array}{l}\text { Men } \\
\mathbf{f}(\mathbf{\%})\end{array}$ & $\begin{array}{l}\text { Both } \\
\mathbf{f}(\%)\end{array}$ \\
\hline $\mathbf{1}$ & Doing terracing & $54(18)$ & $125(41.67)$ & $121(40.33)$ \\
\hline $\mathbf{2}$ & Making contour bund & $30(10)$ & $112(37.33)$ & $158(52.67)$ \\
\hline $\mathbf{3}$ & Building broad bunds & $31(10.33)$ & $117(39)$ & $152(50.67)$ \\
\hline $\mathbf{4}$ & Developing slopping land & $58(19.33)$ & $113(37.67)$ & $129(43)$ \\
\hline 5 & Construction of stone barrier & $109(36.33)$ & $115(38.33)$ & $76(25.33)$ \\
\hline $\mathbf{6}$ & Nursery raising & $29(9.67)$ & $126(42)$ & $145(48.33)$ \\
\hline 7 & Application of organic manure & $83(27.67)$ & $124(41.33)$ & $93(31)$ \\
\hline $\mathbf{8}$ & Mulching \& tree planting activity & $103(34.33)$ & $119(39.67)$ & $78(26)$ \\
\hline
\end{tabular}

*Figure in parenthesis indicate the percentages in respective frequency 
Table.2 Distribution of respondents according to Gender Mainstreaming policies under IWMP $(n=300)$

\begin{tabular}{|l|l|l|l|}
\hline S. No & Policies & No. of respondents & Percentage \\
\hline $\mathbf{1}$ & Reservation policy & 209 & 69.66 \\
\hline $\mathbf{2}$ & Nominated to local decision bodies & 50 & 16.66 \\
\hline $\mathbf{3}$ & Women facilitators & 22 & 7.33 \\
\hline $\mathbf{4}$ & Women staff & 19 & 6.33 \\
\hline
\end{tabular}

Fig.1 Distribution of respondents on the basis of Gender mainstreaming policies

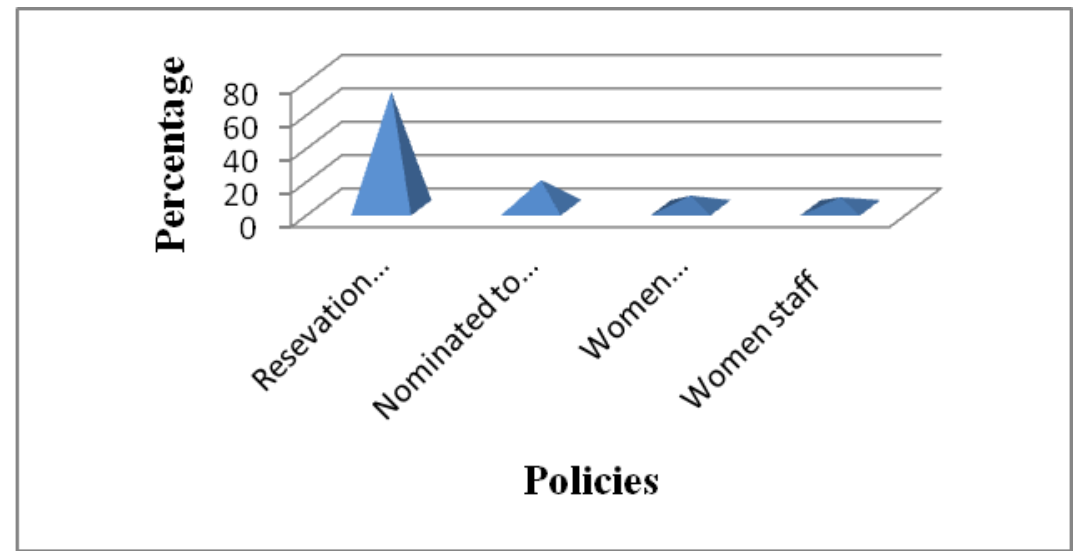

Thus, it can be concluded from data that women's work in hill areas is strenuous and time consuming. In Integrated Watershed Management Project most of the activities were carried out by women. This might be due to lack of off-farm practices and feasibility of agricultural pursuits in economic terms has triggered massive male outmigration. It resulted in shifting of adult members for jobs to support their families economically. Another observation was that women performed most of the labour work and engaged in agricultural operations, this trend remained same. Men in hill region mostly indulged in non-productive activities like gossiping, consumed liqueur, gambling etc. This situation creates an imbalance as all the works were left for the women to perform and enhanced their participation in the region. The findings of the present study are in line with those of Varma and Goldey (1997), Sekabambe and Odong (2008) who reported that majority of farm activities were taken up by women and other activities were carried out by men and women jointly. Singh (2014) found that poor resource management forced males of the region to outmigrate in search of better employment; the burden of livelihood directly falls upon womenfolk and increasing their participation in the economy.

There are some defined policies related to Gender Mainstreaming under IWMP. Data regarding measures taken under Integrated Watershed Management Project is presented in the Table 2. According to the data 69.66 per cent respondents reported reservation policy was the most effective measure to increase women participation in decision making followed by nomination to local decision bodies (16.66 per cent) was the second important measure to increase women participation in decision making in IWMP. There were only 7.33 per cent and 6.33 per cent women mentioned that women facilitators and increased number of women staff were the policies which affected women participation in IWMP. The findings of the study are in line 
with Vasudha (1998) noted that women are nominated to watershed committees under a kind of 'reservation policy', implying that they are not members of the farming community in their own right.

It was observed that in the study area, there was a strong division of power along with a line of culture, tradition, norms, and gender. These differentials make it difficult for women to voice their opinion in public forum. Reservation policy guaranteed women representation in decision making bodies so that women can take their own decisions. Appointment of women facilitators at field levels helped to understand the problems and needs of women beneficiaries. Some changes were observed that women become more comfortable and confident in expressing their views. It can be concluded that these policies to some extent played an important role to reduce the gender gap in Integrated Watershed Management Project. But far-reaching changes are still required to improve the representation of women in decision making and policy structure.

Mountain women are the 'gatekeepers', the 'invisible' managers of the rural economy and key 'players' of household security. Hence, it is argued that their participation remains hugely important in Integrated Watershed Management Project. Therefore by giving attention to gender is essential to sound development practice and at the heat of economic and social progress. Gender sensitive issues should be taken under consideration to enhance women participation. Using gender perspective and enabling the integration of women's knowledge related to environment will increase the chances of environmental sustainability. It is essential for natural resource management projects such as
Integrated Watershed Management and Joint Forest Management projects need to integrate gender perspective at the institutional as well as field level.

\section{References}

CAF. 2010. "Women and natural resources management." Conserve Africa (CAF).

Critchley, W.R.S. and Siegert, K. 1991. Water Harvesting: "A Manual for the Design and Construction of Water Harvesting Schemes for Plant Production". FAO, Rome.

Sekabambe, C.K. and Odong, T. 2008. Division of labour in nakati (Solanum aethiopicam) production in central Uganda. African Journal of Agricultural Research. 3, 400-406.

Singh, S. 2014. Women, Environment and Sustainable Development: A Case Study of Khul Gad Micro Watershed of Kumoun Himalaya, Journal Space and Culture, India, 1 (3), 53-6

United Nations Development Programme. 2004. Governance for Sustainable Human Development. UNDP policy document. New York.

Varma, S.K. and Goldey, P. 1997. Gender roles in farming systems in Haryana state, India: Implications for food security. International Famine Centre, 13p.

Vasudha Lokur Pangare. 1998. "Gender issues in watershed management in India" In AGREN. Network paper No. 88. ISBN 0850033942.

WEDO, 2003. Diverting the Flow: A Resource Guide to Gender, Rights and Water Privatization. Women's Environment and Development Organization, New York

\section{How to cite this article:}

Shikha Singh and Neelam Bhardwaj. 2018. Gender Gap in Integrated Watershed Management Project. Int.J.Curr.Microbiol.App.Sci. 7(09): 345-349. doi: https://doi.org/10.20546/ijcmas.2018.709.042 